
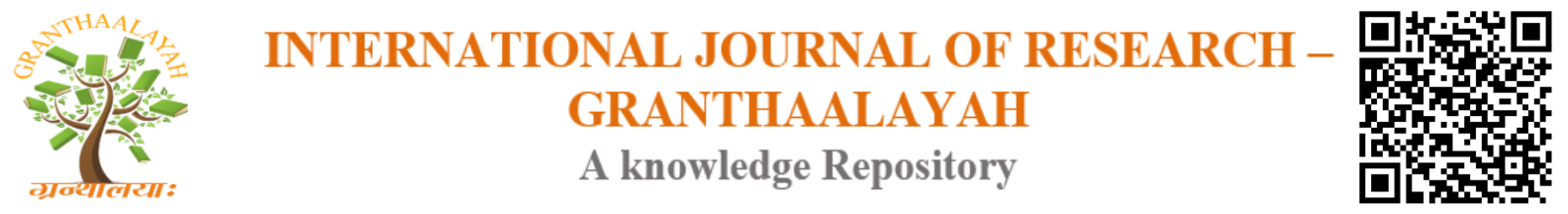

Management

\title{
PRACTICES AND CHALLENGES OF PUBLIC AND PRIVATE PRESCHOOLS OF JIGJIGA CITY ADMINISTRATION
}

\author{
Yigzaw Haile ${ }^{* 1}$, Abdirahman Mohammed ${ }^{2}$ \\ ${ }^{* 1} \mathrm{PhD}$, School of Graduate Studies, Jijiga University, Ethiopia \\ ${ }^{2}$ MA, School of Graduate Studies, Jijiga University, Ethiopia
}

\begin{abstract}
The main purpose of this study was to assess practices and challenges of preschool education in Jijiga City administration. Mixed design was employed (both quantitative and qualitative) for this study. 19 preschool centres (6 public and 13 private preschools) were randomly selected for the study. 51 preschool teachers (12 teachers from public and 39 teachers from private teacher) were selected. A semi-structured questionnaire was used to collect quantitative data in which 57 items were filled by preschool teachers which are dealing with Early Childhood Care and Education (ECCE) practices. Interview, FGD, observation and document analysis were used to triangulate the data collected using questionnaire. Percentage and thematic analysis were used to analyze the quantitative and qualitative data respectively. The main findings revealed that preschool practices in all sampled preschools were found to be below standard, unable to use local stories since teachers were not from the community and knowledge of parents, teachers and principals towards contribution of the preschool was found to be limited. It was found that $82.4 \%$ of the preschool had no early childhood care and education qualification, and $70.6 \%$ of the preschool teachers did not agreed that all sampled preschools had inadequate classroom space, $64.7 \%$ of the preschool centres did not have age appropriate chairs. Similarly, $76.5 \%$ of the preschool had no any out-door playing material and $100 \%$ of all preschool did not used approved curriculum and lack of appropriate teaching used in most of the preschool were some of the main finding. The Ethiopia Somali Regional Education Bureau is recommended to address shortage of trained ECCE teachers, develop standardized ECCE curriculum, applying developmentally appropriate content, materials, and teaching methods, use locally and culturally appropriate materials and assign teachers who can speak the local language of the community.
\end{abstract}

Keywords: Early Childhood Care; Education; Practices; Challenge.

Cite This Article: Yigzaw Haile, and Abdirahman Mohammed. (2017). "PRACTICES AND CHALLENGES OF PUBLIC AND PRIVATE PRESCHOOLS OF JIGJIGA CITY ADMINISTRATION." International Journal of Research - Granthaalayah, 5(12), 17-32. https://doi.org/10.29121/granthaalayah.v5.i12.2017.470. 


\section{Introduction}

\subsection{Background}

Pre-school education is the first step in the child's educational journey. Early childhood experts have the opinion that attending pre-school program, helps to promote children's social and emotional development and prepare them for primary education (Justice \& Vulkelick, 2008). The first five years of life are highly significant, what children learn and feel during this time, particularly about themselves will be foundational to the rest of their life. At this stage a child develops good relationship with people around him (Hightower, 1999). Early childhood is defined as the period from birth to eight years old. This early period is considered to be the most important developmental phase throughout the lifespan. Healthy early child development includes the physical, social-emotional, and language-cognitive domains of development, each equally important -strongly influences well-being, throughout life (Hightower, 1999)

The earliest years of a child's life represent a crucial period of the biological, psychological, social, and emotional growth and change. The first year of life represent a critical window of opportunity in the healthy development of young children; what children learn and feel during this time will be foundational to the rest of their life (Bibi, 2013).

Piaget (1978) envisaged these psychological stages as driven by a process of equilibration. He suggested that children develop schemata to represent their understanding of the world, and that they try to assimilate the world to these schemata until too much external contradiction forces a change and re-equilibration of their world view. The implication of seeing child development as a series of progressive psychological transformations, from one stage to the next, from infancy to maturity, is that these stages become crucial reference points for discussing optimal timing for transitions, e.g., from home to Pre-school or from more informal to more formal curriculum.

Vygotskian theory breaks from traditional developmental psychology by focusing on the importance of social interaction. It emphasizes activity, rather than the individual, as the basic unit of analysis. This more dynamic vision of child development offers a relational view on transitions. In this view, children are actively involved in the timing and quality of their transition experiences. Vygotskian socio-cultural psychology has the advantage of recognizing all aspects of childhood as shaped by social, cultural, and economic processes. This also applies to children's environments, whether these are within the home, the farm, or a preschool setting (Vygotsky, 1998)

In 2014, the global gross enrolment ratio was 44\%, considerably lower than in 2012 as a result of a large downward adjustment to the estimate for India. Indeed, Southern Asia is the region with the lowest participation rate at $18.5 \%$, followed by sub-Saharan Africa (21.5\%) and Northern Africa and Western Asia (29\%). Much higher rates are observed in Latin America and the Caribbean (73\%), Eastern and South-eastern Asia (76\%) and Europe and Northern America (85\%) (UNESCO, 2016)

Between 1999 and 2012, pre-primary enrolment in Sub-Saharan African Countries rose by almost two and half times, but the average gross enrolment ratio (GER) was still very low at only $20 \%$ in 2012. The ratio ranges from less than $2 \%$ in Mali to around $100 \%$ in Ghana, Mauritius, 
and Seychelles. Many countries, including Angola, Cameroon, Equatorial Guinea, Ghana, Lesotho and South Africa, have substantially increased enrolment ratios, albeit some starting from extremely low baselines in 1999. (UNESCO, 2015)

Twenty six countries in Sub-Saharan African Countries had included ECCE in multi-sectoral and sectoral policies and strategic plans, such as Poverty Reduction Strategy Papers (PRSPs), EFA goals, targets for education, and health sector-wide programs or national plans for education, health, nutrition, and protection. Eleven countries have included ECCE in their Fast Track Initiative (FTI) Action Plans (UNESCO, 2010).

Ethiopia is one of the twenty six countries in Sub-Saharan African which has developed ECCE Policy Framework in collaboration with UNICEF and other non-governmental organizations (NGOs). In addition to the ECCE strategic operation plan and guidelines, the new ECCE framework has also been developed that consists of four pillars; 1) Parental education, 2) Health and Early Stimulation Program (Parental to 3+ years), 3) Preschools: community-based kindergartens (4 to 6+ years) and 4) Community-based Non-formal school readiness ((MOE, 2010)

The developed and established Strategic Operational Plan and Guideline for ECCE in the first year of ESDP IV encouraged private investors, faith-based organizations, and NonGovernmental Organizations (NGOs) into delivery of ECCE. The government of Ethiopia has prioritized ECCE in the last years of ESDP IV by establishing of a national steering committee, regional councils, and woreda technical committee (ESDP V, 2015). These efforts have paved the way to high increment of the Gross Enrolment Rate (GER) for pre-primary in Ethiopia to reach 34\% in 2013/14, of which around a quarter is in three-year kindergarten and the remaining was one-year O-Class and Child-to-Child instruction. This is above the ESDP IV target for ECCE which was $20 \%$ (from a baseline of $6.9 \%$ at the start of the plan (ESDP V, 2015). The new ECCE Framework offers a real opportunity to provide universal, low-cost, and quality ECCE in Ethiopia in a long term. However, the Framework is implemented without sufficient extra resources, it is likely to place a significant additional burden on an already overstretched primary education system. (Orkin, et al., 2012)

The Study on the feasibility of ECCE after commencement of ECCE policy that was conducted in SNNPR, Oromia, Tigray, Amhara, Addis Ababa and Benishangul Gumuze has revealed that teachers training (lack of accessible training institute, lack of teachers' trainee and low incentive for ECCE teachers), infrastructure (young children housed in environment that do not meet their developmental needs), awareness at the system level (vary stakeholders appreciation of the importance of ECCE investment, poor dissemination of emerging ECCE framework and action plan), Caregivers perception (poor quality of ECCE lower beneficiary uptake, poor participation paralyzes community and demand and lower awareness of benefit of enrolment), were indicated as major threat and challenges of ECCE supply and demand in Ethiopia (Orkin et al.,2012)

At the national level, 19\% of pupils enrolled in grade 1, in 2006 E.C. (2013/14), have left school before reaching grade 2 in 2007 E.C. (2014/15). Therefore, to decrease the dropout rate at primary school (grades 1 to 8 ), the Ethiopian education system should focus on decreasing the 
number of grade 1 students who dropout, as if grade 1 students are kept in the system the probability of the student dropping out in future grades is less (MoE,2014/15).

One of the main reason why such huge of number of grade 1 drop rate at national level ( $19 \%)$ is contributed to lack of access of any form of early childhood education program before starting in Ethiopia ( MoE, 201/15). Despite of the rapid expansion pre-primary education in Ethiopia that is contributed to introduction of the new ECCE policy framework and its implementation guideline, only 2,958,803 pre-primary school children are enrolled out of the 7,522,942 School age children in Ethiopia, which makes out of the pre-primary school age children, 4,564,139 (MOE, 2014/15). Similarly, Ethiopia Somali Regional Education Bureau has also given due attention to the expansion of the ECCE centers that have improved Gross Enrollment Rate from $1.7 \%$ in 2009/10 to $12 \%$ in 2014/15 G.C. ( Somali REB EMIS, 2014/13).

However, Somali Regional State still have huge number of pre-primary school age children who are out of school. As stated in 2014/15 National Educational Statistical abstract, out of the 490,945 children of appropriate age (4-6) about 60,920 children have only access to preprimary education all over the region while 430,025 children of appropriate age (4-6) are out of the school in the region. Primary school in both urban and rural areas in Somali Region. As stated by some research studies which have been made by different scholars, for instance Amogne Asfaw Eshete (2014) Recently there is considerable expansion of ECCE centers particularly O'classess attached with studied on the impact of attending pre-school education on later academic achievement of students in Dessie, Andualem Tesfay (2014) explored the contribution of community based Early Childhood Care and Education Centers in creating access and delivering quality education for orphan and vulnerable children in Addis Ababa, Rahel Gashaw (2014) focused on quality of Early Childhood Care and Education in Government ECCE centers in Bole and Kirkos Sub-cites in Addis Ababa, Girma Lemma (2014) emphasized on quality of Early Childhood Care and Education in Addis Ababa from the caregiver child interaction, parental perception, and social competence of children (Input-Process-Output Approach) angle. Yigzaw and Srinivas (2015) has conducted a similar study focusing on Practice, benefits and challenges of Early Childhood Care and Education in Government and Private centre of Jijiga City Administration. Most of the above mentioned researches have not focused on the practice and challenges in relation with established policy framework and strategic operational guideline.

\subsection{Statement of Problem}

The first five-year plan of the ESDP-I was launched within the framework of the ETP and the following three year ESDP-II plans did not consider ECCE as absolutely necessary. Not until the third five year, ESDP-III plan was ECCE given the needed policy support by the government to create conducive policy environment and support mechanisms for the participation of various stakeholders. ECCE received much focus in ESDP IV (2010 to 2014/15), which provided a useful analysis of lessons learnt from ESDP III (2005/06 to 2010/11). Tangible program outcomes and targets were set than ever before the preceding ESDPs through different approaches to meet the objective of ECCE as stipulated in EFA documents (Engel, 2010) has placed mainly two key outcome targets: to increase GER from $6.9 \%$ in $2009 / 10$ to $20 \%$ in 2014/15 and to establish a pre-primary class in all rural and urban primary school compounds (MoE, 2010). However, despite the presence of these statements in different sectors of 
governmental policy and the comprehensive inclusion of ECCE in the ESDP IV, ECCE in Ethiopia was one of the most neglected areas (Engel, 2010). Rahel Gashaw (2014) concluded in here study that was conducted in Addis Ababa in her major findings the presence of challenges to meet desired quality in ECCE in terms of ECCE Curriculum, teachers' qualification, teaching and learning process, inadequacy of indoor and outdoor materials. Research conducted by Assefa (2014) revealed that inadequacy of qualified teacher, availability of enough playing ground and materials, child sized table and chairs, classroom space per child, separate rest room for the children, practicing different teaching method safe environment were most challenges faced by the preschool in the study areas. A research conducted by Tigistu (2013) revealed that the majority of the existing personnel working at the different echelons of the education system related to ECCE had irrelevant or only slightly relevant qualifications.

Second Ethiopia EGRA Result ( 2014) showed that a high number of Grade 2 and Grade 3 children were not able to read a single word, which meant that the students were far below benchmark of reading fluency (i.e., 60 words per minute). In Sidama the percentage of nonreaders was 69.2 percent, and in Oromiya it was 41.2 percent. Only Harari (17.9 percent) and Addis Ababa (10.1 percent) had percentages of 0 scores less than 20 percent, with the largest regions (SNNP, Oromiya, Tigray, and Amhara) all having Grade 2 zero scores above 25 percent. Even in Grade 3, significant percentages of children remained nonreaders. The percentage of nonreaders included: Somali (21.4 percent), Amhara (17.0 percent), Sidama (54.0 percent), and Oromiya (20.6 percent). In all eight regions, more than 80 percent of children were not reading at expected fluency benchmarks in 2010 (RTI, 2010). The above result from second EGRA result shows how much contribution of the Pre-school education in Ethiopia is important.

The main key lessons that researcher learned from this EGRA is that major contribution of the preschool for the children that have not experienced early childhood education and that is why children are struggling in grade 1 and 2 in reading, writing and comprehension skills. Although EGRA has forwarded as recommendation for expansion of the access to preprimary in Ethiopia, it has not mentioned clearly key role that preschool can play in addressing these problems. As one of my research questions, the researcher looked at key contribution of the preschool in addressing above mention problems. A lot of gaps have been observed and identified from all above empirical studies mentioned and discussed. All most of the above studies selected and worked on only government run preschools (O'classess). None of them have also placed high emphasis on the key contribution of preschools and included in their research objective and questions as well. Similarly their key research questions and objectives were not looking at actual practices observed in relation with ECCE policy framework and its strategic operation and guideline of Ethiopia and Regional context specific.

Thus based on above empirical researches gaps, the research was interested to examined and explore practice, contribution, and challenges of preschool education as very few research was done in the areas. This research is aimed to address the following major questions

What are the current practices of private and public pre-school Education in Jijiga City administrations (it also considered ECCE input and process, ECCE practice alignment with ECCE policy and quality standard)?

What are the challenges of public and private preschool Education under the study? 


\subsection{Objectives}

The major objective of the study was to:

1) Assess the current practice of the private and public pre-school in Jigjiga city administration in relation with input and process?

2) Identify major challenges public and private schools faces in the implementation?

\section{Methodology}

\subsection{Description of Study Area}

Jijiga City administration is one of the newly established administrations in Ethiopian Somali Regional State. It covers 25 Kilometre square radius that comprised of two woredas of 20 kebeles. There are about 74 preschools out of which 58 are private KGs and while rest 16 are Zero or 0'class- (public pre-preschools). Jijiga City town is roughly $650 \mathrm{Km}$ away from Addis which is located Eastern part of Ethiopia. As current projected population in 2017, Jijiga City is roughly projected around 169,390 (CSA, 2013).

\subsection{Design}

Mixed research design was executed to achieve the objective of the study. This was employed so as to overcome the limitations of a single design and triangulate the data and assure its trustworthiness of the data.

\subsection{Participants}

In the study area 16 public and 58 private pre-school centers are found. Out of 16 public preschools, 6 preschools were selected while 18 private preschool were drawn out of 58 private's preschools. Purposive sampling was used to select 25 participants for FGDs purpose. Five respondents were also purposely selected to conduct interview with them.

\subsection{Instruments of Data Collection}

In this research, different instruments such as questionnaire, interview, FGD, Observation and document analysis were utilized. The content of questionnaire was comprised of background of question (experience, sex, type of school, qualification), inside classroom related setting questions, outside classroom setting related, teaching and learning process, curriculum and syllabi and finally challenges that preschool faced. A set of questions were prepared to collect data from preschool teachers. A total of 42 items were prepared. Three options were given for respondents to choose (Agree, Undecided, and Disagree). The reliability of the questionnaire item were found to be high with Cronbach's Alpha (0.94). So as to consolidate the data gathered using questionnaire, interview was used. Interview and FGD were used to explore early childhood care and education practices and challenges. Besides, a total of 37 questions were prepared and observed from the all sampled preschool. The content of observation checklist covered inside classroom settings (classroom size, classroom per child, light, and ventilation of classroom, and etc.) and outside classroom settings (playing ground, latrines, availability of 
playing materials, water, etc.). Furthermore, document analysis was used in this research work. A total of 5 FGDs were conducted and participants were asked about ECCE practices and challenges. Different documents such as Education Sector Development Plans, policy, National ECCE Quality standards and National Policy framework for ECCE and Strategic plan and guideline for ECCE \& Annual and Regional EMIS were analyzed in this study. The obtained from these documents were used to supplement other data obtained from questionnaire, interview, and FGDs. This has helped the researcher to get answers for all research question articulated.

\subsection{Data Analysis}

Percentage was used to analyze quantitative data. Besides, thematic analysis (zigzag analysis was also considered in due data collection to enrich on-going emerging issue) was employed to analyze qualitative data.

\subsection{Ethical Consideration}

Before the data was collected, the participants were informed and agreed to participate in the study. It was also confirmed that any data would not be disclosed without their consent and keep its confidentiality.

\section{Findings and Discussions}

\subsection{Practices of Early Childhood Care and Education}

\subsubsection{ECCE Teacher's Qualification and Experience}

As it was trapped from the study, vast majority of the respondents represent female which accounts for $62.7 \%$ (32). This figure also reveals that female dominates over male in pre-primary sub-sector as teacher which is in agreement with Early Childhood care and Education Strategy as it calls for teachers assigned in the preschool to have ability to work well with children (MOE, 2010). In this study, qualification of ECCE teachers were explored and it was found out that vast majority of the respondents are certified with diploma which accounts for $60.8 \%$ (31) while rest are $19.6 \%$ (10), $15.7 \%,(8)$ and 3.9\% (2) are certified with certificate, first degree and less than 12 grade respectively. However, $82.4 \%$ (42) respondents are not certified with Early Childhood, Care and Education (ECCE) field of study. Out of the 51 total respondents only $17.6 \%$ (9) have required qualification to teach preschool. This funding is supported by the Rahel (2014) findings in which she found majority of the preschool had no required qualification to teach preschool. Only few respondents had anticipated qualification of certificate on Early Childhood, Care, and Education. During FGD with principles, and teachers, they were asked why preschool is not hiring qualified teachers certified with Early Childhood Care and Education those have knowledge and skills to teach preschool children.

They said that: "it is very difficult to get qualified teachers on Early Childhood, Care and Education, as there are no ECCE professional in the market, then the situation has forced us to 
hire alternatively teacher who have other qualification preferably langue, mathematics and environmental science"

This finding is not in line with what Early Childhood Care and Education strategic operational plan and guideline for Early Childhood Care and Education recommends as minimum qualification required for a preschool teacher. Early Childhood Care and Education strategic operational plan and guideline required all preschool teachers to have minimum Certificate on Early Childhood Care and Education or have attended a 2 months course to upgrade their skills and knowledge, especially in the field of "active learning of young children" ( MOE, 2010).

The ESDP V (2015) acknowledges existence of this challenge and indicates that primary school teachers are using available period to provide zero-Class instruction in the public preschool. It is stated in ESDP V, all College of Teacher Training (CTEs) will start a multi-year diploma specifically for pre-primary teachers to overcome this specific short coming. But it is very evident from the finding that huge gap exists in terms of meeting minimum required qualification for preschool teachers.

Another crucial question that was asked preschool teachers was if they have taken short term training on Early Childhood Care and Education or not and for how long. $47.1 \%$ (24) have not taken any ECCE related training while 23.5\% (12) have taken Early Childhood Care and Education related training more than 6 months period. Even those who have taken short term training more than 6 months, the researchers could not see required practice of Early Childhood Care and Education inside classroom and outside during observation. Based on researchers their own reflection, it was very apparent that preschool teachers had no skills and knowledge on how teacher children. The poor child pedagogical of unqualified teachers had impacted quality of education.

These findings also contrast with target that is set in Ethiopian's Education Strategy Development Program (ESDP V) with regard to the qualified teachers on ECCE. It is noted that in the Regional ESDP V, that 2\% of the preschools will have diploma of ECCE by second year $(2016 / 17)$ of plan. During interview with Ethiopian Somali regional Education Bureau experts and senior management of the bureau confirmed that there is huge gap in the required minimum qualification of the preschool teacher but also informed that there are massive efforts Regional Education Bureau is planning this year (2017) to improve qualification of the preschool teachers by providing multi-year diploma and accelerated ECCE certificate opportunities. The head stated in this way:

"The education bureau is planning to support accelerated Early Childhood Care and Education in-service training to 5,250 teachers through support of General Education Quality Improvement Plan (GEQUI) in this summer program since all are not trained in ECCE”

With regard to preschool teachers' experience, more than $58.8 \%$ (30) have preschool teaching experience more than 5 years followed by $23.5 \%$ (12) who have 1-2 years. $3.9 \%$ (2) and 3-5 years have preschool teaching experience less than one year and 3-5 years respectively. The study depicted that existence of more experience preschool teachers in the pre-primary sub sector 
which is a good opportunity preschoolers and preschool itself. This also shows low preschool teacher turnover

\subsubsection{Inside Classroom Learning Environment}

In the study showed (the tables were not attached for all figures integrated in this study) that 76.5 $\%$ (39) private and public teachers agreed that there was adequate light and ventilation which implies that there are ample windows that light can enter. Only $23.5 \%$ (12) of the respondent's private preschool respondents disagreed that there were adequate light and ventilation inside classrooms. None of the public preschool teachers disagreed that they had no adequate light and ventilation in the classroom. While $23.5 \%$ (12) of the public preschool has agreed that they had adequate light and ventilation in their preschools.

During FGD, teachers were asked why public preschool were all having a better light and ventilation" They said: "UNICEF has supported construction of the building and good and standard design for the preschool classroom that why public preschool have better light and ventilation".

This funding is supported by Tsegaye (2014) findings who has studied on practice and challenge of preschool in Nefasilk sub city of Addis Ababa. Similarly, several others researches, Rahel (2014), and Assefa (2014) supported this findings.

This finding is sin line with Early Childhood Care and Education strategic operational plan and guideline for Early Childhood Care and Education recommends for any preschool room to be well ventilated, with enough window space to allow a good flow of air.

Besides, $70.6 \%$ ( 36) of private preschool teachers has disagreed that they had ample space in the classroom that allowed free movement of the students and teachers, while $5.9 \%$ ( 3 ) private teachers agreed that they had enough classroom space. $23 \%$ (12) of public disagreed that they had enough space in the classroom. All of the preschool teachers agreed that they did not have enough classroom space that allowed. In total 94.1 (23.5\% of public teachers and $70.6 \%$ private teacher) disagreed that they had enough classroom spaces that allowed them to move free.

During FGD with preschool teachers, said that:

"inadequacy of classroom space created difficulty interacting with student in the classroom, and we could not provide necessary support to all children in the classroom, and by nature children \&by nature, children demand close attention and follow up to ensure that they have understood well and benefiting from what is being delivered in the classroom by the teachers"

This was supported by Assefa's (2014) study that most of preschool classrooms observed had inadequate space per child. This finding is also not in harmony with what Ethiopian Early Childhood Care and Education strategic operational plan and guideline for Early Childhood Care and Education as well as national pre-primary quality standard recommends for any child in a given preschool to have 1.55 square meters in the classroom (MOE, 2010). 
In addition, $88.2 \%$ (45) of preschool teachers (23.5\% public teacher, $64.7 \%)$ had disagreed that they had comfortable seating arrangement that allowed free movement and easy interaction with teacher and students. During FGD with teachers, this issue was raised and discussed and teachers said

"Inadequacy of classroom size do not allowed us to change current seating arrangement, this could be changed only if number of the students in the classroom are reduced by constructing additional classroom in the school compound and small chairs that are not taking large space are brought for student in the class, then this problem can be easily tackled but current classroom size cannot allow change seating arrangement"

This finding is supported by Yigzaw and Srinivas (2015) research in which they have found similar findings with regard to seating arrangement of some of the private and public preschool were not suitable and comfortable arrangements. This was against to both National Early Childhood, Care and Education and Strategic Operational plan and guideline for Early Childhood Care and Education that setting of the physical space should allow for free movement of both children and teachers (MOE, 2010). It was further indicated that $62.7 \%$ (32), and 23.5(12) private and public respondents have disagreed that observed sampled preschool were clean and attractive respectively. Age inappropriate chairs were seen in all private and public ECCE centers. This was confirmed in the observation. It was observed that children in the classroom sitting on the over-sized chairs were feeling uncomfortable, of which some of them were even struggling to see teachers and blackboard. The age inappropriate student chairs restricted free movement of children and minimized interaction between students in the classrooms. Play and learning materials were common problems in both private and public ECCE centers. During observation, it was witnessed that few preschools inside classroom's walls were posted on different stimulating things, but the posted materials were not included children's made creative work. The same issue was also raised with teachers and principals as why their preschool's walls were not well decorated, some of the respondents replied that children often detach what is posted on the wall.

Teachers said: "Children often detach what is posted on the wall and while others welcomed the comments and agreed to implement in the upcoming academic year "

\subsubsection{Outside Classroom Physical Settings}

Amazingly, 62\% (32) private teachers replied that they did not have enough playing ground in the preschool compound and all public preschool teachers $(23.5 \%)$ have agreed that they had enough playing materials. During FGD with principals, the same issue was also thoroughly discussed with principals and teachers of the preschool. When they were asked why preschool should not have enough playing ground for the preschoolers, they said

"Our school compound is rented and is not initially built to serve as preschool. During construction of the compound, it was designed to serve as residential place rather than preschool that have large playing ground dedicated for children to play and our preschool is shared with primary school with the same compound". 
This funding is not in line with the National Early Childhood Care and Education Quality Standard, all preschool compound should have minimum of 500- 3,000 meter square (MOE, 2008). In addition, the study confirmed that $76.5 \%$ (23.5\% public and $53 \%$ private) respondents disagreed that they had enough outdoor playing material that children uses. None of the public preschool visited had any outdoor playing materials in their school compound. Inadequacy of outdoor playing in most school findings is supported by Rahel (2014)'s and Yigzaw \& Srinivas (2015) research finding.

When asked some of private preschool teachers and principals about this issue during FGD, they replied: "because of inadequacy of playing ground space in our preschool compound, supply of playing materiel will not possible unless when move the preschool compound that is shared with primary school in the future"

With regard safety of playing ground, $74.5 \%$ (15.7\% public preschool respondents and $58.8 \%$ private preschool respondents did not agree that playing field was safe as there were a lot of gravel rocks littered over the ground. It was also seen during observation; some of the playing grounds were not well prepared and receptive for the young children to play. It was also noted in during observation; safety of the preschool compound is not given high priority. As part of observation, it was found many of the preschool compound were located not far away from the main roads sides where traffic accident are more likely to happen if not paid more attention. Besides, a total of $94.1 \%$ (48) of private and public teachers did not agree that available latrine is adequate and proportionate to the number of the student in the compound. During observation, it was witnessed that available latrines in the schools were shared both preschool children and older children in the primary school that was attached with preschool. In the study, 86.3\% (44) private respondents did not agree that available latrine is not age appropriate. None of the public teacher agreed that they had age appropriate latrine in the school while all of them (23.5 (12) teachers have agreed that they do not use age appropriate. It was also discovered during observation; the few available latrines were not also age appropriate. Only primary student who were sharing the same latrine could use the latrine. Preschool children struggled to use to help of the assistant teachers.

During FGD, one of the parents were asked if he was comfortable his children using age inappropriate: He said "I always ask myself same question how my children use latrine which are not matching their size although teacher told me that they accompany them when they want to use latrine, it worries me too much"

By the same token, $76.5 \%$ (60.8\% private respondents and $15.7 \%$ public respondents) disagreed that they have water tap in their school compound. During FGD, preschool principals were asked why clean water was not available in the compound they replied that:

"The preschool administration is strongly willing to install water in the preschool butt water is not available in the our kebele, and if the city administration make available water at any time in the future, we will be the first one to install water".

This finding is also not line with the Ethiopian National ECCE preschool Quality standard where they suggest that every preschool must have clean water in the compound (MOE, 2008). 


\subsubsection{Preschool Curriculum}

With regard to curriculum $76.5 \%$ (39) of private preschool respondents have agreed that they use curriculum that is developed by the preschool administration. It was noted that most of the private preschool have curriculum that was taken from Addis Ababa different private Kindergartens. Around $23.5 \%$ (12) public preschool respondents disagreed that have their own curriculum for the preschool. During FGD, zero-class teachers were asked why they have curriculum and how did they teach student and they replied:

"The Regional Education did not provide any curriculum to all 0 -classes in the region, and we teach our children based on our experience that is supplemented with what we have got from short term training that is provided by Regional Education Bureau"

Lack of preschool curriculum in the public school has created children not be competent and mater minimum requirement for a child in the preschool to accomplish. This has also created children from public preschool to compete children when they joined upper primary school as their foundation was not strongly built in the preschool they attended. Only quality preschool education can lead to successful transition to primary. This finding has also been supported by Yigzaw and Srinivas (2015) in which they also founded that most of public preschool teacher did not use and follow curriculum.

"Lack of standardization has created problems to the student and teachers, when a student is transferred to our school they often do not immediately get along with our curriculum as we have all different curriculum, and some student require extra support to compete with others who were attending ours school"

During interview with Ethiopian Somali Regional Education head, I asked why standardized curriculum is not yet developed, and he said:

"With support of UNICEF, Somali Regional education bureau is planning to develop a new curriculum for preschools (both Kindergarten and zero-class,) the zero-class's curriculum is already developed only waiting for printing and dissemination".

This finding is in not in harmony with the finding of Rahal (2014), and Tsegaye (2014) where they had found most of government preschool use curriculum that is developed by the Ministry of Education while this finding is in harmony with Yigzaw and Srinivas (2015) where they have found similar finding with regard to unavailability of syllabus and curriculum. Lack of curriculum has brought an impact on children learning process. During FGD, one of the parents, when he was asked about age appropriate of the curriculum said that:

"My children are very much struggling to complete home that is given to them, I often try to help whenever they encounter difficulty but children are taught content that I think is not age wise appropriate. The content of curriculum used are beyond their age".

Even the curriculum which was found in private preschools had different challenges. During observation it was discovered the content of the curriculum had some information that they are 
not familiar with children. Animals like seas fish, whale and zebra, and others were taught which they are not found in their localities.

\subsubsection{Teaching and Learning Process in Preschool Education}

$76.5 \%$ (39) of the private preschool teacher respondents agreed that they use daily lesson in the classroom. While $19.6 \%$ (10) of the public preschool teacher did not agree that they use daily lesson plan. Most of these preschools who did not used lesson were government run zero' classes.

Although government preschool dud not have curriculum to teach student, the lesson plan was not readily available during observation when teacher were requested to show. In all private preschool, all teachers had well planned lesson that is extracted from weekly lesson plan. This was supported by FGD result, where they told us that all preschool did have their own lesson plan in which its content is checked by principals. This finding is in contrast with what Rahel (2014) \& Tsegaye (2014) had found while it is supported by the finding of Yigzaw and Srinivas (2015) findings.

It was very apparent in both private and public, children's interests were not taken into account, children are perceived as passive recipient of the knowledge. When this was asked teachers during FGD as why they did not take into account, they said that:

"Children stage cannot be communicated and it is us who know what is good for them and prepare what we think are good for the children"

It was observed that children were offered nothing inside classroom, children were sitting in the classroom without performing different activities, and this was primarily caused by the lack of adequate learning corner. Private preschool had in better position that public, in some private some story books were offered inside classroom while in all of the public school nothing were offered to the children. The teaching instruction was observed to be lecture based, only teacher are supposed to talk while children are given no time to interact with them. Some private preschool teachers did practice but majority of them were using lecture based teaching method approach which was not child- centred approach. Teaching mother tongue as medium of instruction has significant importance on the learning outcome of the children. UNESCO has encouraged mother tongue instruction in primary education since 1953 \& highlights the importance of mother tongue education right from the start: similarly, Ethiopian Education and Training Policy (ETP), (1994) states "the selection of instructional language is based on the principles of pedagogical advantages, respecting the right of nations and nationalities and also to preserve their culture. As a result of this, primary education should be given in the mother tongue and that of teachers' training institution of this level“". However, it was observed that both in government administered O-classes and private schools, non-Somali speaking were assigned to be teachers in preschool where they can hardly communicate with children. Similarly, children who do not speak Somali language were attending private preschool where teachers cannot speak Amharic language. During observation, it was very apparent that the communication barrier between the teacher and student has created a learning disability. 
In this study, as it was mentioned in FGD and observation.....documentation of children portfolio where all children's progress are recorded and its readily availability to the parent whenever needs arises were asked. Unfortunately, none of the preschool teachers in all sampled preschools (76.5\% private teacher, $23.5 \%$ public teachers) have agreed that they document and maintain children portfolio where all children's progress can be easily found. $100 \%$ of preschool both public and private preschool teachers have agreed that they did not document well.

\section{Conclusion and Recommendation}

Teachers assigned in ECCE were not qualified in the field as the study verified. This would hamper the quality of ECCE program in particular and holistic children development general. Most of the inside classroom practice were found much below standard. Improvement in relation with insufficient classroom space per child, over classroom size, inappropriate, seating arrangements, unbalanced teacher-student ratio and this called to meet desired standard. If this multiple pushing factors are not addressed well, increasing access of the pre-primary education sub-sector will create negative consequence and experience on the child health, and intellectual and mental development. The children need to be more comfortable and feel happy in the classroom. Preschool needs to be more proactive to meet children's interest and needs. Overseized children chair or combined desk used by all preschool was impediment that limited free movement \& positive interaction of teacher and students. Supplying age appropriate chairs and table and combined desk is something that falls within preschool administration control.

Out-door physical setting is another crucial areas that needs a lot investment in all preschool. Most the visited and sampled outdoor physical environment were also found to be much below the national standard: inadequacy of out-door playing materials, lack of playing ground and age inappropriate playing material and insecure playing ground were areas that needed great improvement. It is to be concluded that most of the preschool administration, parents, teachers and local and regional saw play as something that is not crucial for the child's development. Adequate of water, lack of separate latrine for boys and girls, lack of hand washing facilities and age appropriate and proportionate to the number of the student was not given due attention at all. The combinational effect of above challenges could force children to drop out school and create bad experience due to unfavorable physical environment. Children at this age, require close follow up and support they needed. Inexistence of government approved by curriculum, \&lack of cultural and age appropriate were one of the major findings in relation to curriculum. Moreover, lack of syllabi, teacher guide and student text books were major findings. It was very evident that government role in development of curriculum and dissemination was missing. Lack of appropriate curriculum deteriorated quality of education that is desired.

Teaching and learning process practice in both private and public was not as per National ECCE Quality standard. Teacher-centered approach hugely dominated over child-centered approach in both private and public preschool. Children's interest and needs in teaching and learning has never been taken into account. Lecture-based approach lesson delivery was opted as normal lesson delivery. Learning through play in most of preschool visited was rarely practiced. Teachers had barely attempted to develop locally made teaching materials from surrounding. To bring practice with regard to desired teaching and learning process, huge effort is expected both 
government and private sector to uplift lower standard practice to required standard. Few schools had attempted to document children progress that are readily available to the parent whenever need arise. Test and other achievement are only recorded, child's interest and need are seldom documented.

The study recommended that Regional Education Bureau should classify preschool into levels by evaluating them in terms of inputs, process and output and then giving them level (level-1 level 2 level -3 and level -4) based on performance of the preschool. These levels should be known very by the community. Jijiga University should also hold consultative meeting with owners of the private preschool to familiarize existence of opportunity of ECCE Education (Certificate, Diploma, and Degree) in both regular, weekend and summer programs. So improve teaching learning process practices, Jijiga City administration Education office should allocate sizable amount of budget in procuring all required indoor required materials and outdoor playing materials. So as to address constraints with related to inadequacy of in-door and outdoor physical setting, private and public preschool must have a separate compound that is not shared with primary school. To bridge the technical knowledge gap that existed in all preschool in relation to having desired preschool practice, Jigjiga University should select one preschool preferably public preschool where they will demonstrate best practice as per the standard. These preschools will act as model preschool where knowledge hub on preschool practice is found.

\section{References}

[1] Amogne Asfaw Eshetu. (2014). Basic Research Journal of Education Research and Review ISSN 2315-6872 Vol. 4(3) pp. 72-80

[2] Bibi W, Ali A. (2012). The Impact of Pre-school Education on the Academic Achievements of Primary School Students. The Dialogue VII (2):152-159.

[3] CSA. (2013). Population Projection of Ethiopia for All Regions at Woreda Level from 20142017, Addis Ababa.

[4] Hightower J.E. (1999). Caring for People from Birth to Death, Rev. and enlarged ed.

[5] Jean Piaget . (1998) The Collected Works of L.S. Jean Piaget. Volume 5: Child Psychology, New York, NY, Springer.

[6] L. M. Justice \& C. Vulkelick, Achieving Excellence in Preschool Literacy Instruction (New York: Guilford Press, 2008). Learning in Low-resource Settings: Progress and Challenges in Ethiopia, Bernard van Leer Foundation Working Papers in Early Childhood Development 59, The Hague: Bernard van Leer Foundation.

[7] MOE (2015/16). Education Sector Development Program (ESDP). Program Action Plan for ESDP-V. Addis Ababa, Ethiopia: EMPDA

[8] MOE (2014/15), National Education Statistics Abstract, EMIS and ICT, Addis Ababa, Ethiopia

[9] MOE (2010) Strategic Operation Plan for Early Childhood Care and Education for Ethiopia. (Addis Abba: Government of Ethiopia).

[10] MOE (2008). Ethiopia Pre-primary quality standard, Addis Ababa, Ethiopia

[11] Orkin, K. (2012. Are Work and Schooling Complementary or Competitive for Children in Rural Ethiopia? A mixed-methods study. In: Bourdillon, M. and Boyden, J. (Eds.) Childhood Poverty: Multidisciplinary Approaches. Hound mills, Basingstoke: Palgrave Macmillan 298-315.

[12] RTI (2010). Ethiopian Early Grade Reading Assessment: Data Analytic Report, Language, and Early Learning. Addis Ababa: Unpublished.

[13] Rahel Gashaw (2014)., Quality of Early Childhood Care and Education: The case of selected Government ECCE centers in Bole and Kirkos Sub-cites in Addis Ababa, Ethiopia, MA dissertation Addis Ababa University. 
[14] Somali REB (2013/14), Somali Regional Education Bureau Statistics Abstract, EMIS,\& ICT, Jijiga, Somali Region, Ethiopia

[15] Tigistu, K. (2013). Professionalism in Early Childhood Education and Care in Ethiopia: What Are We Talking About?. Childhood Education, 89(3), 152-158

[16] Tsegai Mulugeta (2015) Early child care and education attainment in Ethiopia: Current status and challenges, African Educational Research Journal Vol. 3(2), pp. 136-142, June 2015 ISSN: 23542160

[17] UNESCO (2016). Education for People: Creating sustainable future for all; Global Monitoring report second edition published by UNESCO, Place de Fontenot, 75352 Paris 07 SP, France

[18] UNESCO (2015). Education for All (2000- 2015): Achievement and Challenges, EFA Global Monitoring report

[19] UNESCO (2010). The World Conference on Early Childhood Care and Education, Building the Wealth of Nations, Moscow, Russia Federation

[20] Yigzaw \& Srinivas (2015). Practices, Benefits, and Challenges of Early Childhood Care and Education in Government and Private Centers of Jigjiga City Administration. Proceeding $2^{\text {nd }}$ National Conference on Pastoral Education, and Early Childhood Care and Education, Jigjiga University. 